\title{
POTENTIAL STRATEGIES TO MANAGE BRONZE BEETLE (EUCOLASPSIS SP.) IN ORGANIC APPLE ORCHARDS
}

\author{
D.J. ROGERS ${ }^{1}$, L.M. COLE ${ }^{1}$, T.M. FRASER ${ }^{2}$ and J.T.S. WALKER ${ }^{1}$ \\ ${ }^{1}$ HortResearch, PO Box 1401, Havelock North, New Zealand \\ ${ }^{2}$ Fruition Horticulture (HB) Ltd, 204 Warren St Nth, Hastings, New Zealand
}

Corresponding author: drogers@hortresearch.co.nz

\begin{abstract}
Bronze beetle (Eucolaspsis sp., Coleoptera: Chrysomelidae) threatens the viability of New Zealand's organic pipfruit industry. Small plot cultivation trials were conducted during spring to target immature beetles in the soil in a $2.5 \mathrm{~m}$ strip under apple trees. A single cultivation treatment in October prevented 56 to $81 \%$ of the beetle population from emerging. When plots were tilled every second week from October to December, 79 to $95 \%$ failed to emerge. The pattern and timing of bronze beetle emergence during 2006 was consistent between the four trial orchards and with the 2005 season. A survey of 20 orchards during November 2006 was unable to link beetle damage levels with management practices and the physical environment. New strategies to manage bronze beetle larvae are discussed.

Keywords: bronze beetle, organic apple production, cultivation, Chrysomelidae.
\end{abstract}

\section{INTRODUCTION}

The damaging effects of a small chrysomelid beetle in apple orchards have previously been attributed to Eucolaspsis brunnea (F.), commonly known as bronze beetle (Lysaght 1930; Clearwater \& Richards 1984; Rogers et al. 2006). However, adult beetle samples collected from a single Hawke's Bay orchard during December 2006 were identified as Eucolaspsis pallidipennis (White), (Coleoptera: Chrysomelidae) by Richard Leschen, LandCare Research (voucher specimens were deposited in the NZAC). This species differs from E. brunnea by being slightly smaller with different colouration on the pronotum. Therefore, throughout this paper the pest species studied in Hawke's Bay organic orchards has been referred to as Eucolaspsis sp., pending further taxonomic and distribution studies.

Feeding by adult beetles on flowers and fruitlets can result in severely distorted fruit or raised scab-like blemishes. Feeding on more mature fruit leads to small cavities with distinct chewing marks (Lysaght 1930; Miller 1971). Bronze beetle feeding on apple leaves causes a shot-hole effect but does not result in economic damage. The larvae feed on the small roots of grasses (Miller 1971; Kay 1980). Bronze beetle threatens the viability of organic apple production with some apple cultivar blocks having up to $43 \%$ damaged fruit (Rogers et al. 2006). Other orchards, or particular blocks within orchards, remain unaffected but the pest appears to be spreading to more orchards in Hawke's Bay. There are currently no effective, organically acceptable insecticides to control this pest. Soil cultivation has a long history as an insect control strategy, and was used for bronze beetle control prior to World War II (Lysaght 1930). It has also been used to manage other soil dwelling Coleoptera (Gednalske \& Walgenbach 1984). This study sought to determine the effectiveness of cultivation as a control strategy against immature beetles and to investigate the relationship between beetle damage and orchard factors such as understorey and physical orchard characteristics. 


\section{Sampling immature beetles}

\section{METHODS}

Spade-square soil samples (18 cm spade width, $14 \mathrm{~cm}$ deep) were dug from a block of cv. Royal Gala trees, each less than $1 \mathrm{~m}$ from the base of a trunk, at a Hastings organic orchard (Orchard 2). The aim was to determine when pupae were close to the surface and hence vulnerable to cultivation. Five samples were collected weekly from the same block on four occasions from 14 September 2006. Soil samples were examined by hand and any bronze beetle larvae or pupae found were counted.

\section{Cultivation trials}

The cultivation trials comprised two tillage treatments and an untreated control, each applied to 10-tree plots within rows of apples. A randomised block design was used and each treatment replicated three times. The plots were cultivated by a tractor mounted, off-set rotary hoe (Howard, run at $540 \mathrm{rpm}$ ) to a depth of approximately $7 \mathrm{~cm}$. This large rotary hoe was used to cultivate a $1 \mathrm{~m}$ wide strip, parallel to the row, on both sides of the tree line. The area within the tree line was cultivated using a small domestic rotary hoe to a similar depth (except for orchard 4, which used a custom built between-tree cultivator). Treatments were tested on four organic orchards that had experienced severe bronze beetle damage in previous years. The treated plots were cultivated between 29 September and 10 October 2006. One tillage treatment consisted of a single cultivation (two passes on one occasion), whereas the other treated plots were cultivated again every second week (multiple cultivation, again two passes on each occasion) until 28 December 2006 using a small domestic rotary hoe. These plots were cultivated five to six times, the variation caused by a delayed start at one orchard and declining grower enthusiasm on two orchards prior to Christmas. The plots were monitored weekly from 2 October to 21 December using five bucket emergence traps per plot (Rogers et al. 2006).

\section{Orchard survey}

Damage caused by bronze beetle was assessed in mid-November 2006 (prior to thinning) and in mid-January 2007 (after beetle populations had declined and prior to harvest) on 20 organic orchards in Hawke's Bay. This survey included different blocks within the four orchards where the cultivation trial took place. Orchards were selected to ensure that a wide geographic range, high and low levels of beetle damage, and different management styles were represented. Damage was assessed on 50 bottom tier fruit on each of 20 trees for each cultivar. Three adjacent cultivars (ideally in the same block) were assessed per orchard and the same trees were examined in November and January. During the November assessment the understorey plants were examined using a $1 \mathrm{~m}^{2}$ quadrant near each of four trees per block, and the percentage of bare soil, grasses, clover, broadleaf weeds and other plants was recorded. Furthermore, the type of shelter, soil, adjacent cropping activity and physical features, such as drains, creeks and rivers, were noted for each property.

\section{Data analysis}

Cultivation trial data were analysed separately for each orchard and differences compared by ANOVA, followed by Tukey’s HSD using Minitab ${ }^{\circledR}$ statistical software. Emergence data were analysed using a standard repeated measures model, while differences in damage associated with apple cultivar were compared using a GLM. Both analyses used ANOVA in Genstat ${ }^{\circledR}$. Model adequacy checks were carried out by examining various plots (scatter, histograms and normal probability) of the residuals. 


\section{Soil sampling}

\section{RESULTS}

The number of bronze beetle pupae progressively increased as larvae pupated throughout late September at orchard 2 (Table 1). Furthermore, the majority of immature beetles were found in the top $70 \mathrm{~mm}$ of the soil at this time of the year.

TABLE 1: Mean ( \pm SEM) number of bronze beetle found per spade square soil sample from two depth zones at Orchard 2 in Hawke's Bay in 2006.

\begin{tabular}{lccccc}
\hline & \multicolumn{2}{c}{ Beetles extracted from 0-70 mm } & & Beetles extracted from 70-140 mm \\
\cline { 2 - 3 } \cline { 5 - 6 } Date & Larvae & Pupae & & Larvae & Pupae \\
\hline 14 September & $5.0 \pm 2.3$ & $1.4 \pm 0.9$ & & $0.4 \pm 0.2$ & 0 \\
21 September & $7.3 \pm 2.5$ & $4.7 \pm 1.1$ & & $1.0 \pm 0.4$ & 0 \\
29 September & $1.9 \pm 0.5$ & $7.9 \pm 2.0$ & & 0 & 0 \\
9 October & $0.8 \pm 0.6$ & $9.2 \pm 2.8$ & & 0 & $1.2 \pm 0.8$ \\
\hline
\end{tabular}

\section{Cultivation trials}

Multiple cultivation significantly $(\mathrm{P}<0.05)$ prevented 80 to $95 \%$ of the bronze beetle emerging in the cultivated plots compared to the control (Table 2). A single cultivation in October was less effective (preventing 56 to $81 \%$ from emerging), but was still significantly different compared to the controls at three of the four orchards. While multiple cultivation provided better control than a single cultivation, it was only significantly better at orchards 1 and 3 .

TABLE 2: Mean ( \pm SEM) cumulative emergence of bronze beetle caught per trap in uncultivated, single and multiple cultivation treatments on organic orchards in Hawke's Bay in 2006. Means followed by the same letter within columns are not significantly different (Tukey's HSD, P<0.05).

\begin{tabular}{lcccc}
\hline & \multicolumn{4}{c}{ Orchard } \\
\cline { 2 - 5 } Treatment & 1 & 2 & 3 & 4 \\
\hline Control & $30.6 \pm 1.9 \mathrm{a}$ & $50.3 \pm 6.0 \mathrm{a}$ & $31.0 \pm 5.0 \mathrm{a}$ & $15.4 \pm 2.2 \mathrm{a}$ \\
Single cultivation & $13.5 \pm 0.8 \mathrm{~b}$ & $9.7 \pm 2.2 \mathrm{~b}$ & $10.9 \pm 4.8 \mathrm{a}$ & $5.4 \pm 2.6 \mathrm{~b}$ \\
Multiple cultivation & $6.3 \pm 1.3 \mathrm{c}$ & $7.1 \pm 1.7 \mathrm{~b}$ & $1.7 \pm 0.6 \mathrm{~b}$ & $2.2 \pm 0.6 \mathrm{~b}$ \\
\hline
\end{tabular}

\section{Emergence}

Analysis of adult beetle emergence from the controls of the cultivation experiment demonstrated that bronze beetle populations were significantly higher at orchard 2 than in the other orchards (Fig. 1). Numbers in orchards 1 and 3 were similar but there were fewer in orchard 4 . On average more than $80 \%$ of the beetles emerged during November. Mean cumulative trap catches in the control plots ranged from 15.4 to 50.3 (Table 2), which equates to densities of 269 to 878 beetles per $\mathrm{m}^{2}$. 


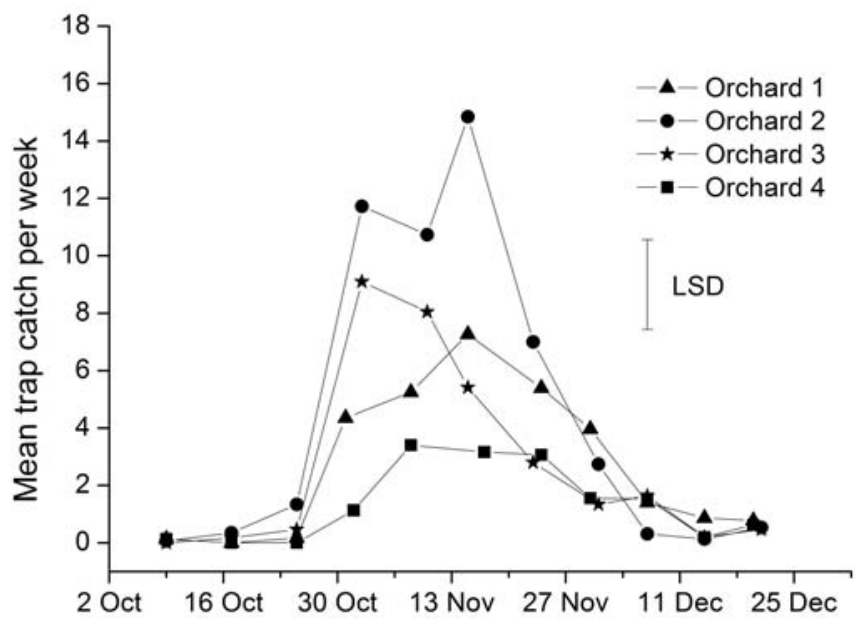

FIGURE 1: Mean number of bronze beetle caught per trap per week in the untreated controls of the cultivation experiment, in four Hawke's Bay organic apple orchards during 2006. The LSD $(\alpha=0.05)$ allows comparison between orchards at the same time points.

\section{Orchard survey}

There was significantly more bronze beetle damage in cv. Royal Gala apples than in the other cultivars examined in mid November (Table 3). Damage to cv. Fuji appeared to be greater than to cv. Braeburn, especially where there were large populations of beetles, although this difference was not significant $(\mathrm{P}>0.05)$. Damage levels caused by this pest varied greatly between orchards. Many had less than $5 \%$ fruit damage while others had 20 to $40 \%$ damage (Table 3; Fig. 2). There appeared to be a higher proportion of fruit damaged when assessed in January compared with November (Fig. 2). There was no correlation between beetle damage to cv. Royal Gala in November and any of the measured understorey characteristics. There was also no apparent relationship with the type of shelter, soil, adjacent cropping activity and physical features, such as drains, creeks and rivers.

TABLE 3: Mean damage by bronze beetle on three apple cultivars recorded in November prior to thinning on organic orchards in Hawke's Bay in 2006. Means followed by the same letter are not significantly different.

\begin{tabular}{lccc}
\hline Cultivar & Mean \% damage & Minimum & Maximum \\
\hline Braeburn & $2.7 \mathrm{a}$ & 0.2 & 12.0 \\
Fuji & $4.7 \mathrm{a}$ & 0.1 & 16.5 \\
Royal Gala & $11.5 \mathrm{~b}$ & 0.1 & 28.1 \\
$\mathrm{LSD}(\alpha=0.05)=3.7, \mathrm{n}=13$ orchards & & \\
\hline
\end{tabular}




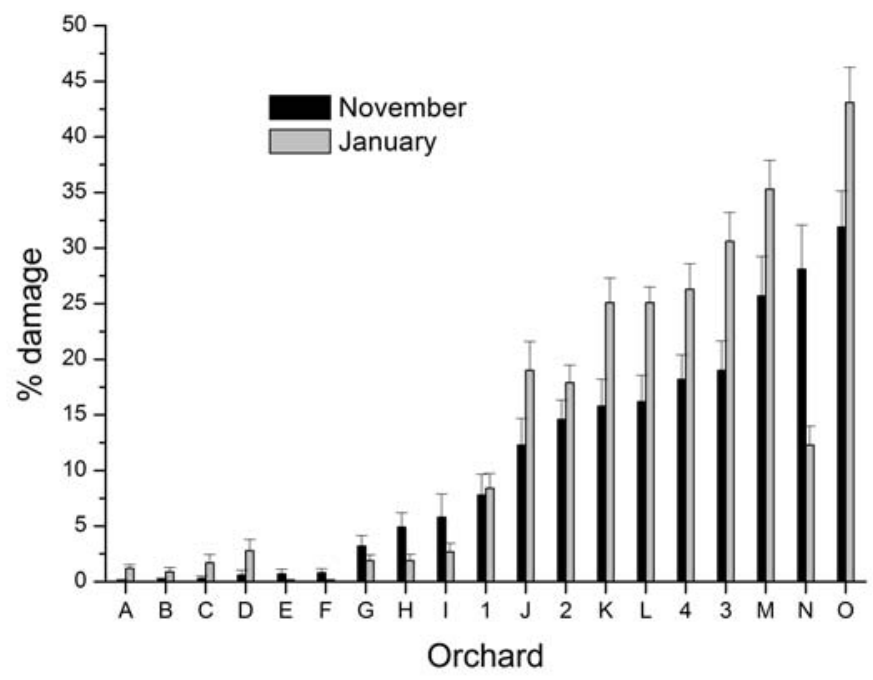

FIGURE 2: Mean ( \pm SEM) percent damaged fruit (cv. Royal Gala) by bronze beetle on 19 Hawke's Bay organic apple orchards examined in mid November 2006 and mid January 2007. Orchards where the cultivations trials occurred have been identified by the appropriate number, although to avoid any bias the damage assessments were made on a different block on the same orchard.

\section{DISCUSSION}

Cultivation during spring was a very successful control measure for reducing bronze beetle in the treated plots, in part because they move close to the surface of the soil prior to pupation (Lysaght 1930). Immediately after the ground had been tilled it was possible to find dead squashed pupae. Pupae appeared to be more susceptible than larvae to damage. Some small lumps of soil were observed after a single tillage treatment (two passes with a rotary hoe) that could potentially contain immature beetles. This may in part explain some of the observed variability among cultivated plots and also among orchards, and highlights the importance of achieving a fine tilth. Another factor influencing variability and overall treatment efficacy may have been the depth of the cultivation, as the rotary hoe could not till greater than $70 \mathrm{~mm}$ and thus could not reach the small proportion of beetles deeper in the soil. Multiple cultivation addressed some of these issues and was therefore more effective. Future work should investigate the efficacy of two or three tillage treatments 1-2 weeks apart starting prior to beetle emergence. Furthermore, the effectiveness of larger scale cultivation on bronze beetle control needs to be determined in combination with wider effects such as root damage.

Bronze beetle emergence in 2006 was consistent between orchards and with 2005 data (Rogers et al. 2006). This suggests that, at least on the Heretaunga plains in Hawke's Bay, it may be possible to recommend that cultivation commences during early October. If orchards in other areas required a different commencement date, bucket emergence traps would be a more efficient monitoring tool than the labour-intensive soil monitoring. The highest density of beetles recorded $\left(878\right.$ beetles per $\left.\mathrm{m}^{2}\right)$ illustrates how severe the problem can be, and underlines the importance of cultivating as much of the area where the beetles are present as possible. 
High levels of damaged fruit recorded at some orchards illustrate the devastation this pest has caused and consequent financial costs. Damage to cv. Royal Gala was greater than cv. Braeburn during the 2006-07 season, consistent with last season's findings (Rogers et al. 2006). There was a trend for cv. Fuji to have more damage than $\mathrm{cv}$. Braeburn supporting anecdotal comments from growers. Damage was assessed during mid November prior to thinning as this enables reliable comparisons to be made between orchards. Assessment of damage in January reflects the damage the orchardist has to their crop from a marketing perspective. However, both November and January measures underestimate total damage, the former because the beetles were still actively feeding till the end of December, and the latter because growers selectively thin beetle-damaged fruit. The effectiveness of thinning as a strategy for managing bronze beetle damage, is limited by crop load, damage levels and cost. Bronze beetle are reported to feed on grasses and clovers (Lysaght 1930; Kay 1980), which may be a factor in why bronze beetle are so common in organic orchards, which have grassed understoreys, compared with orchards using integrated fruit production systems that typically have a herbicide strip. Therefore, there was expected to be a relationship between damage and understorey composition, including bare soil but this was not the case. The distinctive distribution of bronze beetle whereby some blocks and whole orchards remain unaffected is suggestive of some unfavourable environmental factor that limits survival. Unfortunately the present study has not identified such a factor.

More extensive taxonomic studies are required to determine if E. pallidepennis is the beetle species causing damage to other Hawke's Bay orchards, in different regions and also to other horticultural crops. However, Eucolaspsis has complicated species complexes and the taxonomy is relatively unresolved (Dugdale \& Hutcheson 1997).

The findings of this study have identified cultivation as a promising management strategy for the short to medium-term management of bronze beetle in organic orchards. Ultimately a less disruptive control system based upon biological control with entomopathogens and different cultural practices is the long-term goal.

\section{ACKNOWLEDGEMENTS}

Thanks to Hawke's Bay organic growers who participated in this project and especially to Andrew Taylor who kindly lent his offset rotary hoe. Ian Fitch, Sally Adamson and Rebecca Bloomer provided valuable technical assistance. Field scouts from Fruition Horticulture (HB) Ltd carried out the extensive orchard surveys. Financial support for this project was provided by the MAF Sustainable Farming and Pipfruit New Zealand Inc. with in-kind grower support. Mike Butcher (PNZ Inc.) has provided leadership and encouragement for this project. Editorial comments by Peter Lo, John Charles, Sue Zydenbos and David Steven greatly improved this paper.

\section{REFERENCES}

Clearwater JR, Richards MN 1984. Bronze beetle control in Auckland apple orchards. Proceedings of the 37th New Zealand Weed and Pest Control Conference: 235240.

Dugdale JS, Hutcheson J 1997. Invertebrate values of kanuka (Kunzea ericoides) stands, Gisborne Region. Science for Conservation 55. Department of Conservation, Wellington, New Zealand. 17 pp.

Gednalske JV, Walgenbach DD 1984. Effect of tillage practices on the emergence of Smicronyx fulvus (Coleoptera: Curculionidae). Journal of Economic Entomology 77: 522-524.

Kay MK 1980. Bronze beetle. Forest and timber insects in New Zealand No. 49. New Zealand Forest Service, Rotorua, New Zealand. 4 pp.

Lysaght AM 1930. Bronze beetle research. Bulletin 25. New Zealand Department of Scientific and Industrial Research, Wellington, New Zealand. 32 pp.

Miller D 1971. Common insects in New Zealand. AH \& AW Reed Ltd, Wellington, New Zealand. 178 pp.

Rogers DJ, Cole LM, Delate KM, Walker JTS 2006. Managing bronze beetle, Eucolaspis brunnea, in organic apple orchards. New Zealand Plant Protection 59: 57-62. 